Original article

\title{
Do occupational stress and cigarette smoking abet each other: survey of a steel industry in Iran
}

\author{
Fatemeh Fasih-Ramandi ${ }^{1}$, Farshad Nadri ${ }^{2}$, Khaula Atif ${ }^{3}$, Gholamheidar Teimori Boghsani ${ }^{4}$, Hamed Nadri ${ }^{5}$ \\ ${ }^{1}$ Shahid Beheshti University of Medical Sciences, Tehran, Iran \\ ${ }^{2}$ Kermanshah University of Medical Sciences, Kermanshah, Iran \\ ${ }^{3}$ National University of Medical Sciences, Rawalpindi, Pakistan \\ ${ }^{4}$ Torbat Heydariyeh University of Medical Sciences, Torbat Heydariyeh, Iran \\ ${ }^{5}$ Tarbiat Modares University, Tehran, Iran
}

Received 17 April 2018, Revised 16 July 2018, Accepted 8 September 2018

(c) 2018, Fasih-Ramandi F., Nadri F., Atif K., Boghsani G.T., Nadri H.

(C) 2018, Russian Open Medical Journal

\begin{abstract}
Background - Occupational stress antagonizes human health directly as well as by instigating behavioral adversities like smoking; though it's relation with latter is yet unveiled. This study aimed at ascertaining the relation between occupational stresses and smoking status among workers of a steel industry in Iran.

Material and Methods - This cross-sectional descriptive study was conducted among 105 workers of steel industry in Iran. Standardized Health and Safety Executive Management Standards Indicator Tool (HSE-MS IT) along with subjects' demographic features were used to assess occupational stress; while smoking status was measured by standardized methods of Otten et al (1999). Results - Response rate was $86.7 \%$ as 91 completed questionnaires were received back. Mean age of smoking and non-smoking workers $39.5 \pm 10.2 \& 38.4 \pm 5.5$ respectively (data presented as mean with standard deviation - M \pm SD), work experience of smokers and non-smokers $13 \pm 6.1 \& 12.9 \pm 5.9$ years respectively, while $90.4 \%$ were married. Total occupational stress scored $2.96 \pm 0.35 ; 13.5 \%$ staff were at high stress risk. Outcome scores were significantly different between smokers and non-smokers in stress dimensions including role, relationships, managers' support and peer support.

Conclusion - Although smoking workers revealed better situation in role dimension, yet smoking employees depicted higher stress in relationships, managers' support and peer support dimensions. Inferences qualify for imperative measures to implicate smoking cessation programs, as well as regime to attenuate occupational stress at workplaces.
\end{abstract}

Keywords: occupational stress, HSE-MS IT, tobacco, mental health.

Cite as Fasih-Ramandi F, Nadri F, Atif K, Boghsani GT, Nadri H. Do occupational stress and cigarette smoking abet each other: survey of a steel industry in Iran. Russian Open Medical Journal 2019; 8: e0109.

Correspondence to Hamed Nadri. Email: nadri_h@yahoo.com. Phone: +989120849864.

\section{Introduction}

Employees are the nucleus of every industry. Their work earns them bread and butter, but with an association of a multitude of job related stressors. Occupational stress is defined as experiencing negative emotional states like frustration, apprehension, anxiety and depression at workplaces [1]. Disparities between work demand/pressures and employees' capabilities/knowledge generates such scenarios [2]. It breeds psychosomatic symptoms like job dissatisfaction, hypertension, musculoskeletal or neuro-cardiologicals signs and behavioral deterioration as social withdrawal, precluded collegial harmony or substance abuse $[3,4]$. This forecasts costly aftermaths for the individuals as well as organizations. Apropos, role of occupational stress at workplaces cannot be overemphasized.

Health and Safety Executive report [1] documented prevalence of work related stress in Great Britain as 1510 per 100,000 personnel. The average stress-induced lost days per head were 23.9 days in $2015 / 16$. Stress causes $37 \%$ of all work related ailments and loss of $45 \%$ working days. Work pressures, scares managerial support, violence and prevailing uncertainty are the major accomplices of professional strain [1].

Smoking like other behavioral changes as produced by job constraints is a sheer health hazard $[5,6]$, although association between the two is persistently under-investigated and undiagnosed [7]. Cigarette smoking is a vital public health dilemma $[8,9]$. It may lead to accidents preceded by distractions or inattention which it fetched [10]. In Iran, $13.9 \%$ of general population smoke [8], 75 thousand succumb to death annually because of tobacco and nicotine smoking [11]

Kouvonen et al. established an association between work stress and smoking; people with high effort-reward imbalance or lower rewards had a high probability of smoking, necessitating implementation of smoking cessation programs at workplaces [7]. Other literature defied such relation $[12,13]$. 


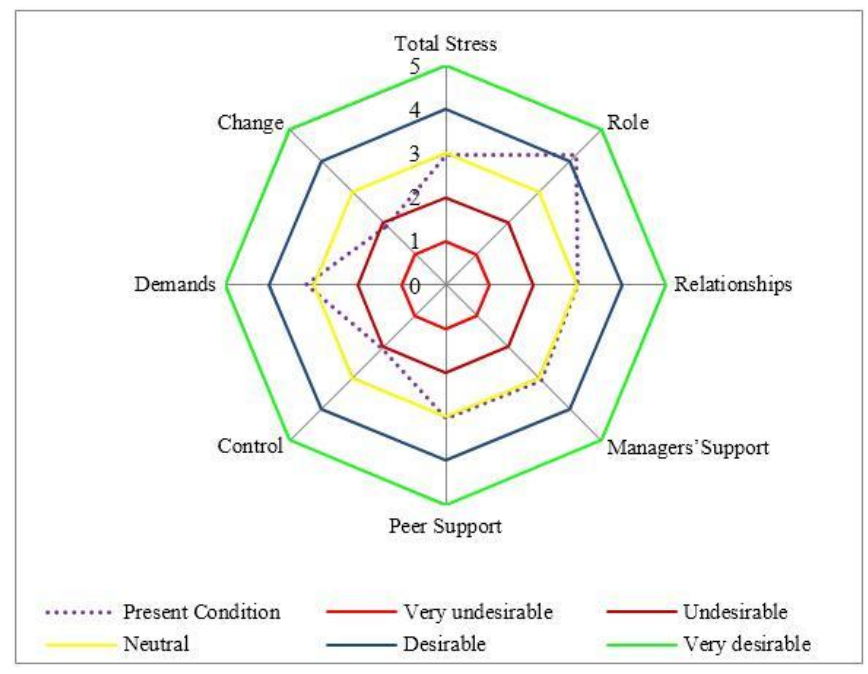

Figure 1. Comparison of mean score of total occupational stress and HSE-MS IT dimensions with desirability level in steel industry workers.

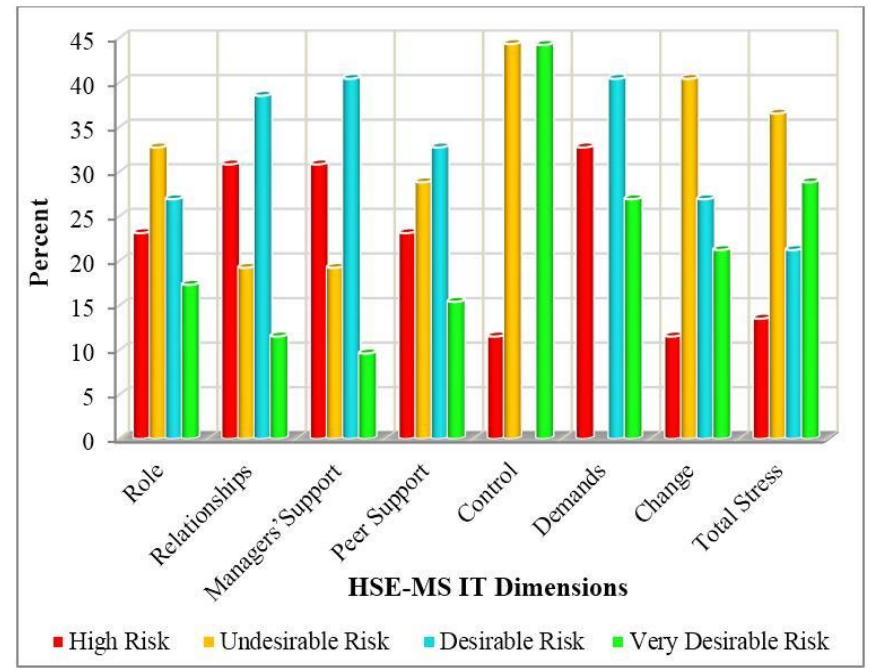

Figure 2. Comparison of percentage distribution of HSE-MS IT dimensions with benchmark data in the steel industry workers.

A multitude of inventories have been developed to evaluate occupational stress. One of the most important instrument being the Health and Safety Executive Management Standards Indicator Tool (HSE-MS IT) [1], having an acceptable validity and reliability [14], and has been frequently used [15-17]. It was validated in Iran by Marzabadi et al [18]. It provides with mean score for each of the 7 dimensions; organization's performance in each dimension can be gauged by comparing with reference data [19-21]. This study probed into occupational stress and smoking status among workers of one of the steel industries in Iran.

\section{Material and Methods}

\section{Study design and participants}

This cross-sectional descriptive analytical study was conducted under the kind supervision of student research committee of Shahid Beheshti University of Medical Sciences, in
2017, in a steel industry of Southern Iran. All 105 male workers in this industry were enrolled. Data collected via HSE-MS IT [1].

\section{Occupational stress assessment}

Standardized HSE-MS IT questionnaire has 35 -items and seven dimensions; demands ( 8 items), control (6 items), managers' support (5 items), peer support (4 items), relationships ( 4 items), role (5 items) and change ( 3 items). First four indicate job-content, rest specify the job context. Responses are scored on a five-point Likert scale, from 1-5(very undesirable to very desirable). Two alternative response formats were used: a frequency response (always to never) and an agreement format (strongly disagree to strongly agree). According to HSEMS IT, higher scores indicated a lower stress risk [19]; scores below 20th percentile reflected high stress risk, 20-50 ${ }^{\text {th }}$ percentile meant undesirable category, $50-80^{\text {th }}$ percentile showed desirable category and 80th percentile and above were the very desirable category, as this classification is also called benchmark data [4, 19]. Reliability and validity of this questionnaire in Iran was approved by Marzabadi et al. with Cronbach's alpha $=0.78$ [18].

\section{Demographic and smoking assessment}

Demographic variables including age, marital status, education level, work experience and smoking habit were also gathered to rule out their possible relation with outcome variable. To enhance trust and comfort, the purpose of study was elucidated to every worker, there was no pressure of any type and informed consent was taken from every respondent. Smoking was measured using standardized methods presented by Otten et al. [13]; which divide smoking intensity into 3 categories; light smoker (1-9 cigarettes), medium smoker (10-19 cigarettes) and heavy smoker (20 or more cigarettes) [7, 13]. All subjects who had smoked three or more cigarettes per day over the previous month were labeled as smokers by self-reporting data. Only adult male aging less than 60 years served in the subject industry, therefore, senior citizen males and females from any age-group could not be enrolled in this survey.

\section{Statistical analysis}

Data analyzed via IBM-SPSS 22 . Normality was determined by Kolmogorov-Smirnov test. Relationships between demographic characteristics (marital status and smoking habit) and education level with mean score of occupational stress were examined by independent sample T-test and Kruskal Wallis test respectively. $p<0.05$ was considered the level of significance. Quantitative data presented as mean with standard deviation - M \pm SD.

Results

Response rate was $86.7 \%$ as 91 completed questionnaires were received back. Mean age of smoking and non-smoking workers $39.5 \pm 10.2 \& 38.4 \pm 5.5$ respectively, work experience of smokers and non-smokers $13 \pm 6.1 \& 12.9 \pm 5.9$ years respectively, while $90.4 \%$ were married. Education levels of $26.9 \%, 13.5 \%$, $42.3 \%$ and $17.3 \%$ subjects were Diploma, Associate degree, Bachelor and Master of science respectively. All smokers were medium smokers as stated, so our parameters were confined to non-smokers and medium smokers only; latter being $48.1 \%$. 
Table 1. The relationship between occupational stress score with workers demographic characteristics

\begin{tabular}{|c|c|c|c|}
\hline \multicolumn{2}{|c|}{ Variables } & $\begin{array}{l}\text { Occupational } \\
\text { stress score }\end{array}$ & p-level \\
\hline \multirow[t]{2}{*}{ Smoking habit } & Smoking & $2.62 \pm 0.12$ & \multirow{2}{*}{$0.001^{*}$} \\
\hline & Non-smoking & $3.27 \pm 0.11$ & \\
\hline \multirow[t]{2}{*}{ Marital status } & Single & $2.84 \pm 0.33$ & \multirow{2}{*}{$0.440 *$} \\
\hline & Married & $2.97 \pm 0.35$ & \\
\hline \multirow[t]{4}{*}{ Educational level } & Diploma & $3.01 \pm 0.39$ & \multirow{4}{*}{$0.670 * *$} \\
\hline & Associate degree & $2.79 \pm 0.28$ & \\
\hline & Bachelor of science & $3.00 \pm 0.33$ & \\
\hline & Master of science & $2.91 \pm 0.38$ & \\
\hline \multirow[t]{4}{*}{ Experience } & $<6$ & $2.85 \pm 0.37$ & \multirow{4}{*}{$0.706 * *$} \\
\hline & $6-12$ & $3.01 \pm 0.30$ & \\
\hline & $12-18$ & $2.97 \pm 0.34$ & \\
\hline & $>18$ & $2.96 \pm 0.42$ & \\
\hline \multirow[t]{4}{*}{ Age } & $26-34$ & $2.82 \pm 0.31$ & \multirow{4}{*}{$0.001 * *$} \\
\hline & $34-42$ & $3.07 \pm 0.30$ & \\
\hline & $42-50$ & $3.17 \pm 0.38$ & \\
\hline & $>50$ & $2.56 \pm 0.04$ & \\
\hline
\end{tabular}

Data presented as mean with standard deviation $-\mathrm{M} \pm \mathrm{SD}$.

${ }^{*}$ - T test; ${ }^{* *}$ - Kruskal Wallis test.

Table 2. The relationship between different dimensions of occupational stress and smoking habit

\begin{tabular}{llllll}
\hline Dimensions & $\begin{array}{l}\text { Non- } \\
\text { smoking }\end{array}$ & $\begin{array}{l}\text { Benchmark } \\
\text { comparison }\end{array}$ & Smoking & $\begin{array}{l}\text { Benchmark } \\
\text { comparison }\end{array}$ & $\begin{array}{c}p \text { - } \\
\text { level }\end{array}$ \\
\hline Role & $3.95 \pm 0.46$ & $<50$ th perc. & $4.48 \pm 0.29$ & $<50$ th perc. & 0.001 \\
Relationships & $3.96 \pm 0.24$ & $<50$ th perc. & $1.98 \pm 0.36$ & $<50$ th perc. & 0.001 \\
Managers' & $4.02 \pm 0.31$ & $<80$ th perc. & $2.01 \pm 0.33$ & $<80$ th perc. & 0.001 \\
support & & & & & \\
Peer support & $3.97 \pm 0.39$ & $<50$ th perc. & $2.04 \pm 0.43$ & $<50$ th perc. & 0.001 \\
Control & $2.02 \pm 0.22$ & $<80$ th perc. & $2.04 \pm 0.26$ & $<80$ th perc. & 0.819 \\
Demands & $3.15 \pm 0.32$ & $<80$ th perc. & $3.17 \pm 0.15$ & $<80$ th perc. & 0.861 \\
Change & $1.90 \pm 0.37$ & $<50$ th perc. & $1.86 \pm 0.40$ & $<80$ th perc. & 0.753 \\
\hline
\end{tabular}

Data presented as mean with standard deviation $-\mathrm{M} \pm \mathrm{SD}$. perc., percentile.

Figure 1 compares disability level with scores of HSE-MS IT dimensions. The occupational stress scored $2.96 \pm 0.35$. Highest and lowest scores were related to the role $(4.21 \pm 0.47)$ and change $(1.88 \pm 0.39)$ dimensions respectively. Average control dimension score was $2.03 \pm 0.24$. Other dimensions including relationships, managers' support, peer support and demands scored 3.01 \pm 1.05 , $3.06 \pm 1.06,3.04 \pm 1.06$ and $3.16 \pm 0.26$ respectively (Figure 1 ).

The desirability levels of HSE-MS IT dimensions in comparison with benchmark data are presented in Figure 2. Among HSE-MS IT dimensions including role, relationships, managers' support, peer support, control, demand and change, 23.1, 30.8, 30.8, 23.1, 11.5, 32.7 and 11.5 percent of workers were placed in the high stress risk category respectively. High risk category workers were $13.5 \%$ (Figure 2).

There was a significant link between dependent variable and smoking status $(p=0.001)$ or age group $(p=0.001)$; non-smokers and middle aged people depicted more scores and lesser stress; whereas marital status $(p=0.440)$, experience groups $(p=0.706)$ and educational level $(p=0.670)$ could not cast significant impacts (Table 1).

The independent T-test showed that average scores of outcome in dimensions of role, relationships, managers' support and peer support among smokers and non-smokers were statistically significant; regarding others (control, demands and change), it remained insignificant. Compared to the benchmark data, the average scores of managers' support, control and demands dimensions among non-smokers and smokers, as well as change dimension in smokers were above the 50th percentile, while all other scales were between the 20th and the 50th percentile (Table 2).

\section{Discussion}

Job stress is a well-recognized yet sparsely reconnoitered workplace menace. Its ability to cast detrimental effects on workers' mental and physical health remains underestimated till today. HSE-MS IT instrument was used in this project as it assesses professional strains in seven relatively independent dimensions rather than a total stress score [21]. The response rate was almost $100 \%$, which was heartening once compared with similar surveys [22-24]; it also augmented reliability of the results.

Cigarette smoking may get catastrophic in terms of physical or biological disasters like fires/explosions, health hazards and toxicities or mental diversions with resultant accidents [10]. Preventive measures are highly deemed in current era of its high prevalence of $48.1 \%$.

The average occupational stress scores remained between 20th-50th percentile; creating alarms and necessitating imperative constructive regimes. The stress scores of $13.5 \%, 36.5 \%, 21.5 \%$ and $28.8 \%$ employees were respectively found as high risk, undesirable, desirable and very desirable categories. Among all dimensions about 50\% subjects depicted high and undesired stress. Similar inferences are documented by Modarresi et al [25] and Gharibi et al [26].

There was no significant relationship between independent variable and work experience; confirming results of Daniali et al. [27] and Lotfizadeh et al. [28]; while contradicting those of Gharibi et al. [26], Modarresi et al. [25] and Nadri et al. [29]. No significant relationship was found between the outcome and marital status which is in line with Modarresi et al. [25] and contrasts Aghilinejad et al. [30]. Similarly, there was no significant relationship between stress and educational level, supporting Modarresi et al. [25] and Gharibi et al. [26]. Regarding age group, workers aging 26-34 and greater than 50 years' had lower scores; indicating higher stress risk. This finding defied data of Nadri et al. [29], while agreed with Kayastha et al. [31].

Smoking had a strong positive relationship with job stress levels. A significant difference was also reported between dimensions of occupational stress including relationships, managers' support and peer support with smoking habit; smokers had lower score (higher stress) than non-smokers.

Therefore, because of the financial burden of occupational stress (prevalence and incidence rate and lost work days due to it), preventive measures smoking cessation programs may beneficial as a modification measures to reduced occupational stress and productivity gains $[1,32]$. It should be noted that strong smoking prevention strategies, may result in blaming the victim [7].

Relationship dimensions at work have been defined as avoiding conflict and unacceptable behavior with colleagues. Also, managerial and peer support dimensions included encouragement and provision of resources by them. Apparently there was no proper relationship between colleagues in this work environment with smokers. Additionally, smokers lagged support from managers as compared to non-smokers. Role dimension has been 
defined as clarity and lack of conflict in the worker's roles in workplaces. The reported significant difference between role dimension and smoking habit showed that smoking workers have higher score (lower stress) than non-smoking workers; which meant former had a better understanding of their role. These results were in agreement with Kouvonen et al [7], which established a relationship between high effort-reward imbalance and being a smoker. Intensity of smoking has also been associated with higher job strain, higher effort-reward imbalance and other dimensions (low job controls and rewards). Some literature had denied any association between job stress and smoking $[12,13$, 33]. Few researchers proclaimed smoking as a way to cope with stress or adverse circumstances [34, 35].

Role, relationships and peer support dimensions among both non-smoking or smoking workers and change dimension among non-smoking workers compared to the benchmark data unambiguously need amendments [4, 36]. Dimensions of demands (workload, work pace and work environment), control (workers control on their work) and change (manage and notify change within the organization) have no significant impact on smoking habit. Job stress in these dimensions requires improvement once compared with benchmark data $[4,36,37]$.

This research carried some limitations. Firstly, this is a crosssectional study which describes associations between variables, not causal or across-time relationships. Secondly, these results were self-reporting, so data could be less objective than that obtained via medical files or examination. The selection and interview bias cannot be over-ruled. Nevertheless, it is the first and pioneer study of its type to be carried out in subject workplace, utilizing standardized and validates inventories. In future, it can give way forward to scientists to conduct similar surveys with bigger sample size, better variables and more vast results.

\section{Conclusion}

Occupational stress casts imminent effects on physical, mental and behavioral health of every individual of any organization. Smoking being a candid abettor further maligns the situation, ensuing a vicious cycle. Modifiable factors like smoking and nonmodifiable aggravators such as age must be promptly addressed to break this detrimental play of cause and effects. It is opined to hold managerial training and smoking cessation programs at all tiers.

\section{Conflict of interest}

The authors declare that they have no conflict of interest

\section{Ethical approval}

All procedures performed in studies involving human participants were in accordance with the student research committee of the Shahid Beheshti University of Medical Sciences (Tehran, Iran), and with the 1964 Helsinki declaration and its later amendments or comparable ethical standards.

\section{Acknowledgments}

This study was related to the project NO. 1395/74139 from Student Research Committee, Shahid Beheshti University of Medical Sciences, Tehran, Iran. The authors appreciate the "student research committee" and "research and technology chancellor" in Shahid Beheshti University of Medical Sciences (Tehran, Iran) for their financial support of this study.

\section{References}

1. Health and safety at work: Summary statistics for Great Britain 2016. Health and Safety Executive, 2016. http://www.hse.gov.uk/statistics/overall/hssh1516.pdf?pdf=hssh1516.

2. Stavroula L, Griffiths A, Cox T. Work organisation and stress: systematic problem approaches for employers, managers and trade union representatives. Geneva: World Health Organization, 2003; 27 p. http://www.who.int/iris/handle/10665/42625.

3. Hansen J, Sullivan B. Assessment of workplace stress: Occupational stress, its cons and common causes of teacher stress. New York, USA McGraw Hill, 2003: 611-623. https://eric.ed.gov/?id=ED480078.

4. Marcatto F, Colautti L, Filon FL, Luis O, Di Blas L, Cavallero C, et al. Work-related stress risk factors and health outcomes in public sector employees. Safety Science 2016; 89: 274-278. https://doi.org/10.1016/j.ssci.2016.07.003.

5. Bergen AW, Caporaso N. Cigarette smoking. J Nat Cancer Inst 1999; 91(16): 1365-1375. https://www.ncbi.nlm.nih.gov/pubmed/10451441.

6. Pearson TA, Blair SN, Daniels SR, Eckel RH, Fair JM, Fortmann SP, et al. AHA Guidelines for primary prevention of cardiovascular disease and stroke: 2002 Update: Consensus panel guide to comprehensive risk reduction for adult patients without coronary or other atherosclerotic vascular diseases. American Heart Association Science Advisory and Coordinating Committee. Circulation 2002; 106(3): 388-391. https://www.ncbi.nlm.nih.gov/pubmed/12119259.

7. Kouvonen A, Kivimäki M, Virtanen M, Pentti J, Vahtera J. Work stress, smoking status, and smoking intensity: an observational study of 46190 employees. J Epidemiol Community Health 2005; 59(1): 63-69. https://doi.org/10.1136/jech.2004.019752.

8. Moosazadeh M, Ziaaddini H, Mirzazadeh A, Ashrafi-Asgarabad A, Haghdoost AA. Meta-analysis of smoking prevalence in Iran. Addiction Health 2013; 5(3-4): 140-153. https://www.ncbi.nlm.nih.gov/pubmed/24494171.

9. Ezzati M, Henley SJ, Thun MJ, Lopez AD. Role of smoking in global and regional cardiovascular mortality. Circulation 2005; 112(4): 489-497. https://doi.org/10.1161/CIRCULATIONAHA.104.521708.

10. Leistikow BN, Martin DC, Jacobs J, Rocke DM, Noderer K. Smoking as a risk factor for accident death: a meta-analysis of cohort studies. Accid Anal Prev 2000; 32(3): 397-405. https://doi.org/10.1016/S00014575(99)00034-2.

11. Nakhaee N, Ziaaddini H, Karimzadeh A. Epidemiologic study on drug abuse among first and second grade high school students in Kerman. Addict Health 2009; 1(1): 31-36. https://www.ncbi.nlm.nih.gov/pubmed/24494080.

12. Landsbergis PA, Schnall PL, Deitz DK, Warren K, Pickering TG, Schwartz JE. Job strain and health behaviors: results of a prospective study. Am J Health promot 1998; 12(4): 237-245. https://doi.org/10.4278/08901171-12.4.237.

13. Otten $F$, Bosma $H$, Swinkels $H$. Job stress and smoking in the Dutch labour force. Eu J Pub Health 1999; 9(1): 58-61. https://doi.org/10.1093/eurpub/9.1.58.

14. Edwards JA, Webster S, Van Laar D, Easton S. Psychometric analysis of the UK Health and Safety Executive's Management Standards workrelated stress Indicator Tool. Work Stress 2008; 22(2): 96-107. https://doi.org/10.1080/02678370802166599.

15. Marcatto F, Colautti L, Larese Filon F, Luis O, Ferrante D. The HSE Management Standards Indicator Tool: concurrent and construct validity. Occup Med (Lond) 2014; 64(5): 365-371. https://doi.org/10.1093/occmed/kqu038.

16. Mucci N, Giorgi G, Cupelli V, Gioffrè PA, Rosati MV, Tomei F, et al. Work-related stress assessment in a population of Italian workers. The Stress Questionnaire. Sci Total Environ 2015; 502: 673-679. https://doi.org/10.1016/j.scitotenv.2014.09.069.

17. Rosati MV, Di Giorgio V, Fidanza L, Di Marzio A, Suppi A, Sacco C, et al. Work-related stress: evaluation in two working populations. Prev Res 2015; 4(3): 111-120. https://doi.org/10.11138/PER/2015.4.3.111. 
18. Azad M, Gholami F. Reliability and validity assessment for the HSE job stress questionnaire. J Behavior Sci 2011; 4(4): 291-297. http://www.behavsci.ir/article 67703.html.

19. MacKay CJ, Cousins R, Kelly PJ, Lee S, McCaig RH. 'Management Standards' and work-related stress in the UK: Policy background and science. Work Stress 2004; 18(2): 91-112. https://doi.org/10.1080/02678370410001727474.

20. Kerr R, McHugh M, McCrory M. HSE Management Standards and stress-related work outcomes. Occup Med (Lond) 2009; 59(8): 574579. https://doi.org/10.1093/occmed/kqp146.

21. Cousins R, Mackay CJ, Clarke SD, Kelly C, Kelly PJ, McCaig RH. 'Management Standards' work-related stress in the UK: practical development. Work Stress 2004; 18(2): 113-36. https://doi.org/10.1080/02678370410001734322.

22. Gardner $\mathrm{DH}$, Hini $\mathrm{D}$. Work-related stress in the veterinary profession in New Zealand. N Z Vet J 2006; 54(3): 119-124. https://doi.org/10.1080/00480169.2006.36623.

23. Hansez I, Schins F, Rollin F. Occupational stress, work-home interference and burnout among Belgian veterinary practitioners. Ir Vet J 2008; 61(4): 233-241. https://doi.org/10.1186/2046-0481-61-4$\underline{233}$.

24. Verrier W, Harvey J. An investigation into work related stressors on diagnostic radiographers in a local district hospital. Radiography 2010; 16(2): 115-124. https://doi.org/10.1016/j.radi.2009.09.005.

25. Modarresi M, Shooferian-Yazdi GR, vakili M, Aghakoochak A, Modarresi MS, Meydani M. Occupational stress among the staffs of health centers in Yazd in 2016. Social Determinants of Health 2017; 3(1): 3-8. http://doi.org/10.22037/sdh.v3i1.16494.

26. Gharibi V, Malakouti J, Arsang Jang S, Gholami A. Prevalence of occupational stress and its relationship to individual characteristics in tunneling industry workers. Health Sys Res 2013; 9(1): 57-65. https://www.sid.ir/En/Journal/ViewPaper.aspx?ID=333342.

27. Daniali S, Shahnazi H, Kasiri Dowlatabadi N, Hasanzadeh A, Sharifirad G, Rabiie L. Job satisfaction among healthy workers, Khomeinishahr, Iran. Health Sys Res 2011; 7(6): 702-709.

28. Lotfizadeh M, Noor-hassim I, Habibi A. Analysis of occupational stress and the related issues among employees of Esfahan steel company (ESCO), Iran (2009). J Shahrekord Uni Med Sci 2011; 13(5): 37-45. Persian. http://journal.skums.ac.ir/article-1-916-en.html.

29. Nadri F, Nadri A, Nadri F, Haidari E, Akbari $H$, Akbari $H$, et al. The job stress among tellers and its affecting factors. I Health Policy Sustainable Health 2014; 1(2): 59-63. https://journals.bmsu.ac.ir/jhpsh/index.php/jhpsh/article/view/15.

30. Aghilinejad M, Attarchi M, Golabadi M, Chehregosha H. Comparing stress level of woman nurses of different units of Iran university hospitals in autumn 2009. Ann Mil Health Sci Res 2010; 8(1): 44-48. URL: http://journals.ajaums.ac.ir/article-1-562-en.html.

31. Kayastha D, Kayastha R. A study of occupational stress on job satisfaction among teachers with particular reference to corporate, higher secondary school of Nepal: Empirical study. Asian j Mgmt Sci Edu 2012; 1(2): 52-62. http://www.ajmse.leenaluna.co.jp/AJMSEPDFs/Vol.1(2)/AJMSE2012(1.2-06).pdf.

32. Guthrie R, Ciccarelli M, Babic A. Work-related stress in Australia: The effects of legislative interventions and the cost of treatment. Int J law Psychiatry 2010; 33(2): 101-115. https://doi.org/10.1016/j.ijlp.2009.12.003.

33. Reed DM, Lacroix AZ, Karasek RA, Miller D, Maclean CA. Occupational strain and the incidence of coronary heart disease. Am J Epidemiol 1989; 129(3): 495-502. https://doi.org/10.1093/oxfordjournals.aje.a115160.

34. Robbins MC, Kline A. To smoke or not to smoke: A decision theory perspective. Soc Sci Med 1991; 33(12): 1343-1347. https://doi.org/10.1016/0277-9536(91)90277-J.

35. Stronks K, van de Mheen HD, Looman CW, Mackenbach JP. Cultural, material, and psychosocial correlates of the socioeconomic gradient in smoking behavior among adults. Prev Med 1997; 26(5): 754-766. https://doi.org/10.1006/pmed.1997.0174.
36. Rondinone BM, Persechino B, Castaldi T, Valenti A, Ferrante $P$, Ronchetti $\mathrm{M}$, et al. Work-related stress risk assessment in Italy: the validation study of health safety and executive indicator tool. $G$ Ita Med Lav Ergon 2012; 34(4): 392-399. https://www.ncbi.nlm.nih.gov/pubmed/23477105.

37. Sancini A, Ricci S, Tomei F, Sacco C, Pacchiarotti A, Nardone N, et al. Work related stress and blood glucose levels. Ann Ig 2017; 29(2): 123 133. https://doi.org/10.7416/ai.2017.2139.

\section{Authors:}

Fatemeh Fasih-Ramandi - MSc, Student of Occupational Health Engineering, Student Research Committee, Shahid Beheshti University of Medical Sciences, Tehran, Iran. https://orcid.org/0000-0001-5003-7846.

Farshad Nadri - PhD, Department of Occupational Health Engineering, School of Health, Kermanshah University of Medical Sciences, Kermanshah, Iran. http://orcid.org/0000-0001-8773-2981.

Khaula Atif - MBBS, MCPS, DPH, Health Care Administrator, National University of Medical Sciences, Rawalpindi, Pakistan https://orcid.org/0000-0002-4977-4459.

Gholamheidar Teimori Boghsani - MSc, Department of Environmental and Occupational Health, School of Public Health, Torbat Heydariyeh University of Medical Sciences, Torbat Heydariyeh, Iran. https://orcid.org/0000-00034908-4324.

Hamed Nadri - PhD Student, Department of Occupational Health, School of Medical Sciences, Tarbiat Modares University, Tehran, Iran https://orcid.org/0000-0002-5221-7098. 